\title{
APLIKASI SISTEM PENILAIAN PERKEMBANGAN ANAK PADA POS PAUD ABIMANYU
}

\author{
Sardiarinto ${ }^{1}$, Gunawan Budi Sulistyo ${ }^{2}$, Lina Ayu Safitri ${ }^{3}$, Sri Kiswati ${ }^{4}$ \\ Universitas Bina Sarana Informatika \\ sardiarinto.sdo@bsi.ac.id ${ }^{1}$, gunawan.gnw@bsi.ac.id ${ }^{2}$, lina.las@bsi.ac.id ${ }^{3}$, sri.srk@bsi.ac.id $^{4}$
}

\begin{abstract}
Abstrak
Pendidikan anak usia dini adalah tempat untuk mengembangkan semua potensi yang dimiliki anak secara optimal. Guru sebagai pendidik memberikan rangsangan pada semua aspek perkembangan anak melalui kegiatan bermain yang menyenangkan. Guru sebaiknya memberikan nilai untuk anak didiknya sesuai dengan perkembangannya masing - masing. Agar perkembangan anak dapat dipantau dengan baik. Maka dari itu, kegiatan bermain perlu dinilai ketepatannya, peralatannya, tujuannya, tempat dan waktunya. Tentunya untuk menilai mengalami kendala atau kesulitan. Guru harus mampu menggunakan instrumen, metode, dan teknik yang tepat dalam memberikan penilaian. Teknologi perlu dimanfaatkan untuk memaksimalkan proses penilaian perkembangan anak pada POS Pendidikan Anak Usia Dini ABIMANYU pada saat ini. Model proses pengembangan Aplikasi yang digunakan adalah metode waterfall mulai dari analisa kebutuhan, kemudian dilanjutkan dengan design sistem dan software, pembuatan kode program dan pengujian. Penelitian ini menghasilkan Aplikasi penilaian perkembangan anak menggunakan teknologi berbasis web yang mampu mempermudah proses penilaian perkembangan anak oleh guru PAUD serta mampu menghasilkan laporan yang cepat, tepat dan akurat.
\end{abstract}

Kata Kunci: Aplikasi Sistem, Penilaian Perkembangan Anak, Web PAUD

\begin{abstract}
Early childhood education is a place to optimally develop all potential that the children have. Teachers as educators provide stimulation to all aspects of child development through fun play activities. Teachers should give grades to their students according to their respective developments so that the child development can be monitored properly. Therefore, play activities need to be assessed in terms of accuracy, equipment, purpose, place and time. When doing assessment, teachers may encounter obstacles or difficulties. They must be able to use the right instruments, methods and techniques in providing assessments. The technology needs to be utilized to maximize the process of assessing child development in ABIMANYU's early childhood education at this time. The application development process model used is the waterfall method starting from needs analysis, then continued with system and software designs, program code creation and testing. This study yields an application of child development assessment using web-based technology that can make the process of assessing child development by early childhood teachers easier and is able to produce fast, precise and accurate reports.
\end{abstract}

\section{Keywords: System Applications, Child Development Assessment, PAUD Web}

\section{PENDAHULUAN}

Sangaltah penting untuk memantau pertumbuhan dan perkembangan anak usia dini. Pendidikan anak usia dini adalah tempat untuk mengembangkan semua potensi yang dimiliki anak secara optimal. Guru sebagai pendidik memberikan rangsangan pada semua aspek perkembangan anak melalui kegiatan bermain yang menyenangkan. Maka dari itu, kegiatan bermain perlu dinilai ketepatannya, peralatannya, tujuannya, tempat dan waktunya. Guru sebaiknya memberikan nilai untuk anak didiknya sesuai dengan perkembangannya masing-masing. Agar perkembangan anak dapat dipantau dengan baik. Supaya nantinya memudahkan guru dalam memberikan pembelajaran selanjutnya(Khairi, 2018). Sehingga peran guru yang berkompenten sangat diperlukan agar penerapan pembelajaran bisa optimal.
Sedangkan untuk mengukur hasil proses pembelajaran sesuai dengan rencana yang tertulis dalam Penyusunan Rencana Pelaksaan Pembelajaran Harian (RPPH), didalamnya tertulis rencana penilaian atau evaluasi. Jadi, selain menyusun rencana pembelajaran sekaligus dengan menyusun rencana evaluasi. Pada kenyataannya di lapangan masih dijumpai dokumen RPPH yang tidak memuat rencana evaluasi. Hal ini membuat proses pembelajaran menjadi tidak terukur ketercapaiannya(Hani, 2019). Rencana evaluasi sangat penting, untuk megetahui hasil capaian pembelajaran, dan juga untuk meningkatkan kualitas pembelajaran di waktu mendatang.

Sistem penilaian di PAUD berbeda dengan penilaian pada jenjang pendidikan diatasnya. Untuk penilaian di PAUD difokuskan bukan pada hasil belajar anak tetapi pada bagaimana anak belajar. Guru merekam perilaku anak 
dalam berbagai instrument penilaian untuk memantau perkembangan anak dan menentukan intervensi atau stimulus yang tepat untuk anak. Pemantauan perkembangan anak akan semakin baik apabila guru mampu mengolah potongan - potongan dari fakta yang terekam didalam instrumen-instrumen menjadi data yang menunjukkan capaian perkembangan pada aspek nilai, moral, dan agama, kognitif, bahasa, fisik motorik, sosial emosional dan seni(Jaya, 2019). Tentunya untuk menilai mengalami kendala atau kesulitan. Beberapa kesulitan yang dihadapi oleh guru dalam membuat penilaian perkembangan anak dapat dikelompokkan ke dalam empat tahap, yakni perencanaan penilaian, pengumpulan data, analisis data, dan pelaporan serta tindak lanjut hasil penilaian(Gomes, 2019). Sehingga perlu solusi yang tepat terkait kendala yang dialami guru dalam menilai perkembangan anak supaya didapatkan hasil yang optimal.

Menurut (Iswantiningtyas \& Wulansari, 2018) mengemukakan bahwa,"Guru harus mampu menggunakan instrumen, metode, dan teknik yang tepat dalam memberikan penilaian agar hasil penilaiannya tepat dan akurat. Melalui penilaian, guru dapat mengetahui fungsi proses pembelajaran, terutama yang berkaitan dengan metode, materi dan perilaku anak selama proses pembelajaran berlangsung". Sedangkan menurut (Nurhayati \& Rakhman, 2017) mengemukakan bahwa baik lembaga PAUD, guru PAUD ataupun orangtua harus paham akan pentingnya asesmen pembelajaran dan perkembangan anak untuk memonitor tumbuh kembang anak. sehingga dapat saling bersinergi untuk mengevaluasi tumbuh kembang anak dalam segala bentuk aspek untuk menetapkan suatu pendekatan pendidikan yang sesuai bagi setiap anak. Oleh katena itu sangat diperlukan kerjasama antara guru, lembaga PAUD dan orangtua

Sesuai dengan perkembangan jaman, memasuki abad ke - 21 bangsa Indonesia mengalami kemajuan perkembangan ilmu pengetahuan dan teknologi yang sangat pesat. Hal ini ditunjukkan dengan adanya informasi dan komunikasi yang menyebar secara cepat disetiap aspek kehidupan, termasuk dalam dunia pendidikan. Seiring dengan hal tersebut, dunia pendidikan juga mengalami dampak yang signifikan. Dampak itu membawa pengaruh positif maupun negative secara langsung terhadap proses pendidikan(Hardiyana et al., n.d.).

Menurut (Febrialismanto, 2020) mengemukakan bahwa saat ini tugas guru PAUD untuk mengembangkan perkembangan anak yang sesuai dengan perkembangan TIK sangat diperlukan. Sedangkan menurut
(Prabowo \& Agustina, 2017), berpendapat bahwa sistem informasi pengolahan nilai sangat diperlukan untuk mengelola raport. Dengan adanya sistem ini akan memudahkan guru, wali kelas, maupun bagian pengajaran dalam pengolahan data dan nilai siswa guna penyusunan raport. Dengan demikian guru sangat berperan untuk menjalankan sistem informasi pengolahan data yang digunakan di lembaga PAUD.

Penelitian dengan judul "Perancangan Sistem Informasi Penilaian Siswa Taman Kanak-Kanak Pada Ra.Darussalam Tangerang Berbasis Web "(Erliyani \& Putri, 2019) menghasilkan sistem informasi yang dapat digunakan untuk menilai raport per semester tetapi untuk penilaian harian belum ada di aplikasi.

Pada lembaga POS PAUD Abimanyu pemberian nilai dilakukan setiap hari menggunakan catatan manual kemudian diakhir semester melakukan rekapitulasi. Untuk memudahkan rekapitulasi maka perlu dikembangkan sebuah aplikasi sistem penilaian perkembangan anak berbasis web yang mampu mempermudah proses penilaian perkembangan anak baik nilai harian ataupun nilai semesteran serta mampu menghasilkan laporan yang cepat, tepat dan akurat.

\section{METODOLOGI PENELITIAN}

Pengembangan aplikasi ini dibangun menggunakan metode RAD (Rapid Application Development). Model RAD merupakan proses pengembangan software yang menerapkan pengembangan siklus yang sangat pendek yang merupakan adaptasi dari model air terjun/waterfall(Utami, 2015).

Berikut langkah - langkah dalam membuat aplikasi menggunakan model (Utami, 2015):

1. Pemodelan Bisnis

Dalam tahap pemodelan bisnis berisi tentang Informasi apa, yang menghasilkan siapa, yang memproses siapa dan berasal dari mana informasinya.

2. Pemodelan Data

Pada tahap melakukan identifikasi karakteristik serta hubungan - hubungan antar objek.

3. Pemodelan Proses

Dalam tahap ini, objek data dihubungkan untuk melaksanakan fungsi tersebut.

4. Generalisasi Aplikasi

Tahap ini merupakan proses menghasilkan aplikasi menggunakan Bahasa pemrograman.

5. Pengujian Merupakan proses pengujian komponen dan interface dari program. 


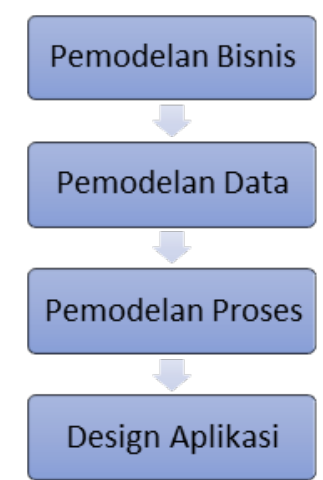

Gambar 1. Metode RAD(Rapid Application Development )

III. PEMBAHASAN

3.1. Pemodelan Bisnis

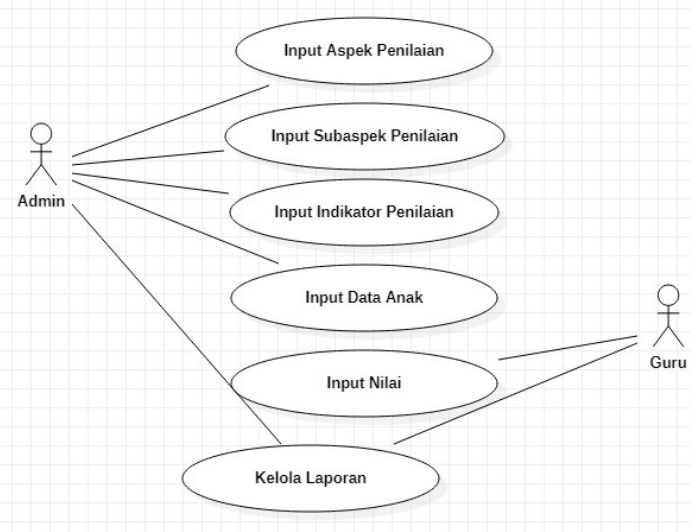

Gambar 2. Pemodelan Bisnis

Tahapan - tahapan dalam proses bisnis diaplikasi ini sebagai berikut:

1. Admin dapat melakukan input Aspek Penilaian

2. Admin dapat melakukan input SubAspek Penilaian

3. Admin dapat melakukan input Indikator Penilaian

4. Admin dapat melakukan input Data Anak

5. Guru dapat menginput nilai anak

6. Admin dan Guru dapat melihat laporan Nilai

\subsection{Pemodelan Data}

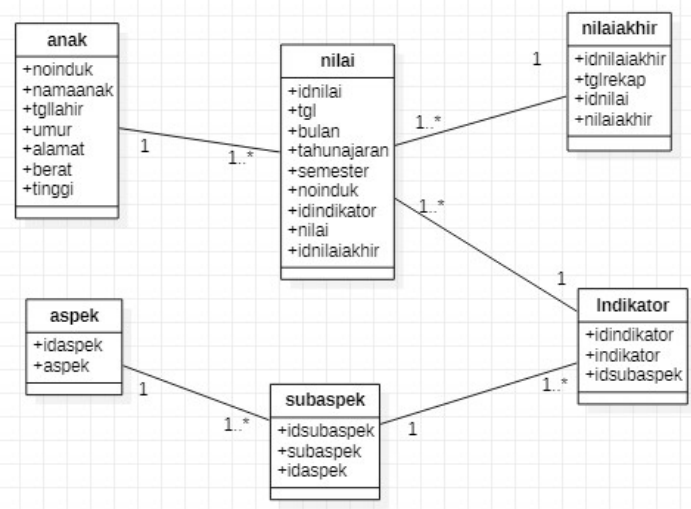

Gambar 3. Pemodelan Data

\subsection{Pemodelan Proses}

\subsubsection{Proses Input Aspek Penilaian}

Dalam diagram activity berikut dijelaskan mengenai fungsi yang digunakan dalam melakukan penginputan data Aspek Penilaian yang dilakukan oleh Admin. Model diagram activity dapat dilihat dalam gambar 4 dibawah ini.

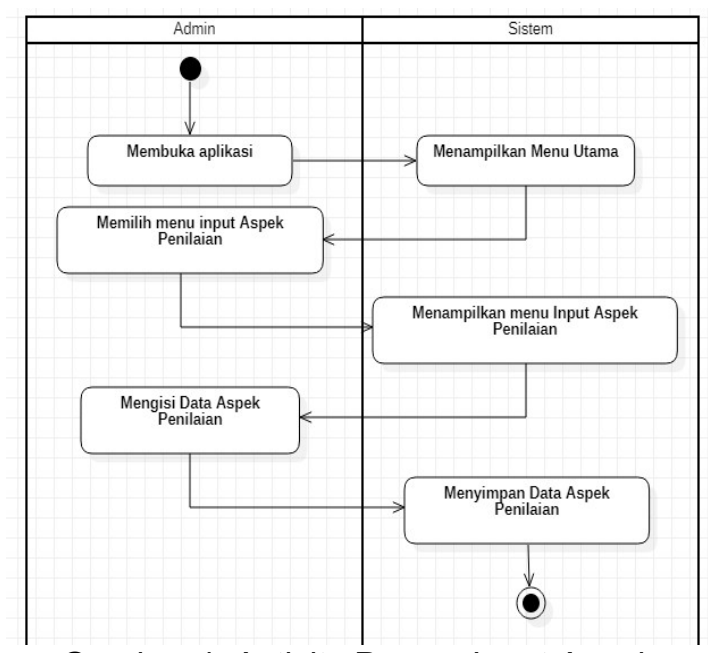

Gambar 4. Activity Proses Input Aspek

Penilaian

3.3.2. Proses Input Subaspek Penilaian

Dalam gambar diagram activity 5 dibawah ini dijelaskan mengenai fungsi yang akan digunakan dalam melakukan proses input data Sub Aspek Penilaiam yang dilakukan oleh pihak Admin.

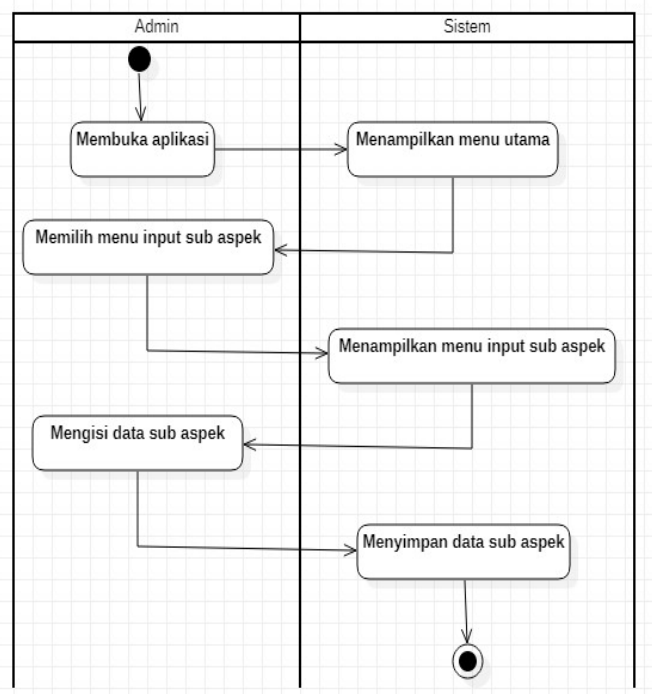

Gambar 5. Activity Proses Input Sub Aspek Penilaian

\subsubsection{Proses Input Indikator Penilaian}

Fungsi yang akan digunakan dalam input data Indikator Penilaian oleh Admin dapat dilihat dalam diagram activity gambar 6 berikut ini. 


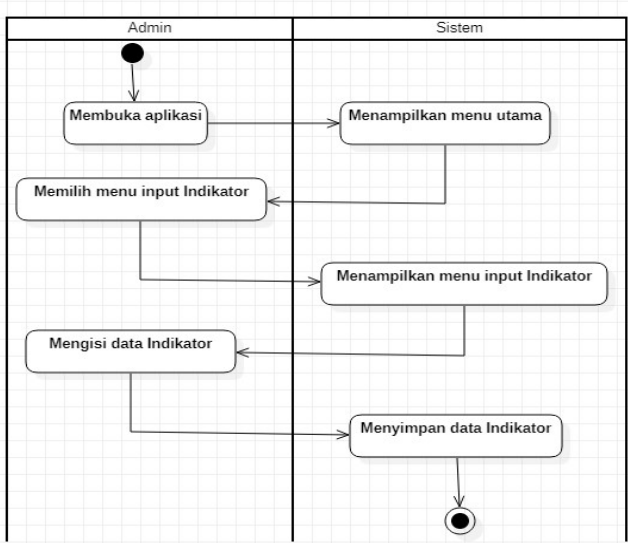

Gambar 6. Activity Proses Input Indikator Penilaian

\subsubsection{Proses Input Data Anak}

Gambar 7 dibawah ini menunjukkan diagram activity yang menjelaskan tentang fungsi yang akan digunakan untuk melakukan input data anak didik yang dilakukan oleh Admin.

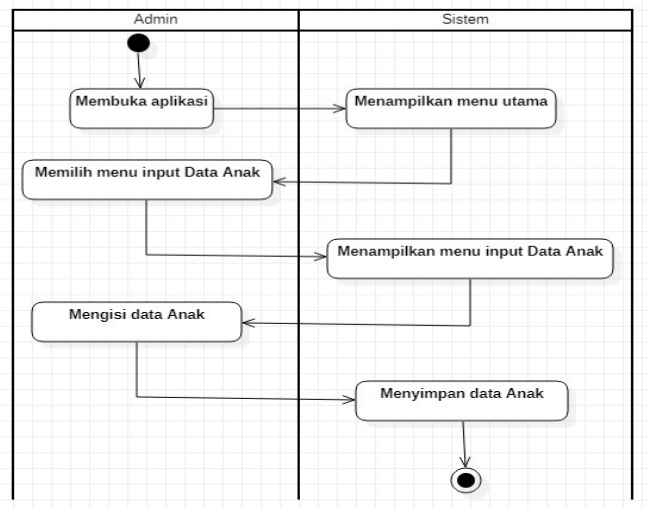

Gambar 7. Activity Proses Input Data Anak

\subsubsection{Proses Input Nilai}

Fungsi yang akan digunakan untuk melakukan input data nilai dari anak didik yang dilakukan oleh Guru dapat dilihat pada gambar diagram activity gambar 8 berikut ini:

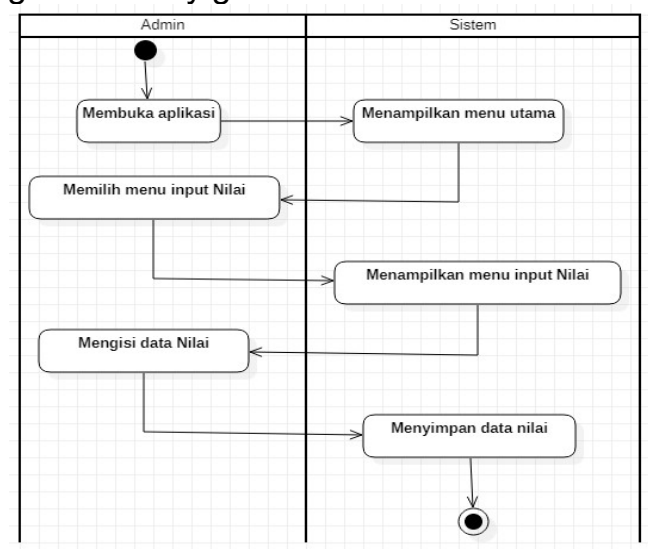

Gambar 8. Activity Proses Input Data Nilai

\subsubsection{Proses Pengelolaan Laporan}

Diagram activity terakhir yang menjelaskan tentang fungsi yang akan digunakan untuk melakukan pengelolaan laporan yang dilakukan oleh Guru dan Admin dapat dilihat sebagai berikut:

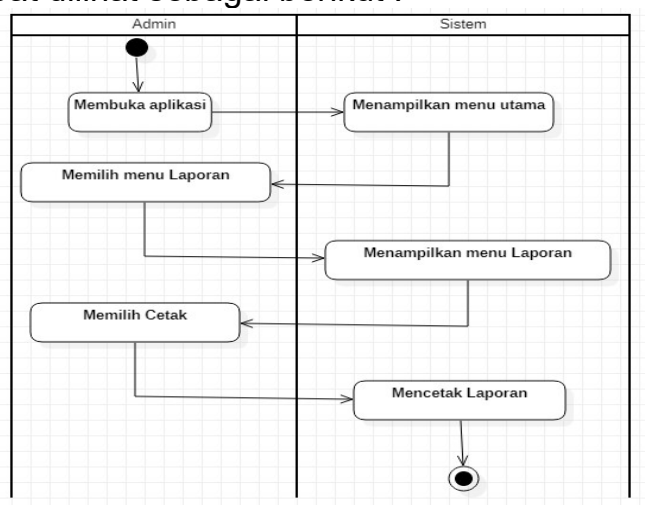

Gambar 9. Activity Proses Pengelolaan Laporan

\subsection{Pembentukan Aplikasi}

\subsubsection{Tampilan Menu Utama}

Ketika pertama kali aplikasi dibuka akan muncul Menu utama yang berisi pilihan mulai dari Data Aspek Penilaian, Data Subaspek Penilaian, Data Indikator Penilaian, Data Anak, Data Nilai dan Kelola Laporan. Tampilan menu utama dapat dilihat pada gambar 10 berikut :

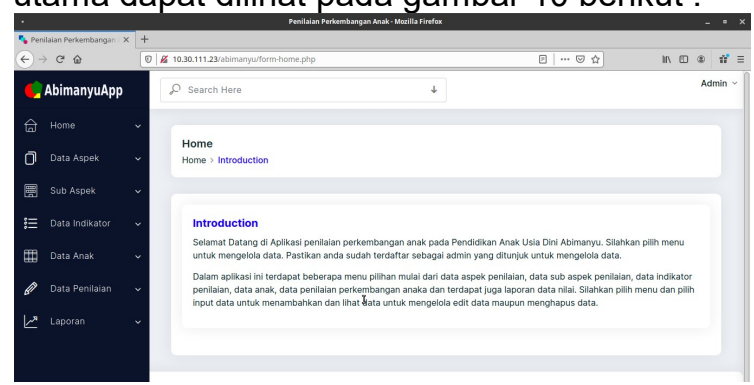

Gambar 10. Halaman Menu Utama

\subsubsection{Input Aspek Penilaian}

Dalam data Aspek penilaian dapat dilakukan penambahan data melalui menu ini. Isikan data kode aspek, aspek penilaian kemudian klik tombol simpan untuk menyimpan data. Klik tombol batal untuk membatalkan. Tampilan menu input aspek penilaian dapat dilihat pada gambar 11 .

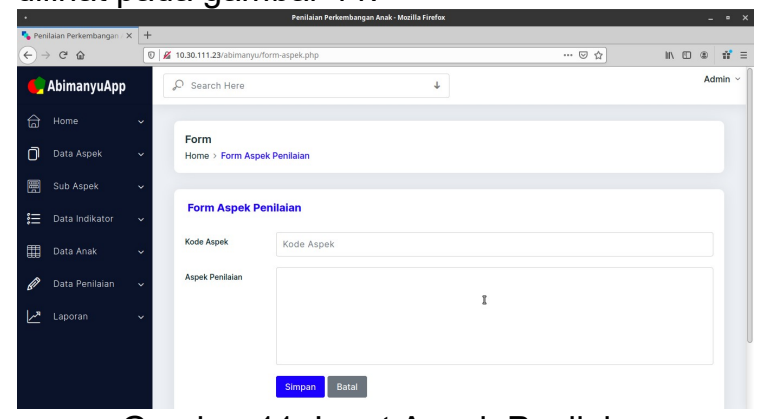

Gambar 11. Input Aspek Penilaian 


\subsubsection{Input Subaspek Penilaian}

Gambar 12 dibawah ini menunjukkan tampilan menu input subaspek penilaian. Dimana dalam menu Sub Aspek penilaian ini dapat dilakukan proses penambahan data dengan cara mengisikan data kode subaspek, sub aspek penilaian kemudian klik tombol simpan untuk menyimpan data. Klik tombol batal untuk membatalkan.

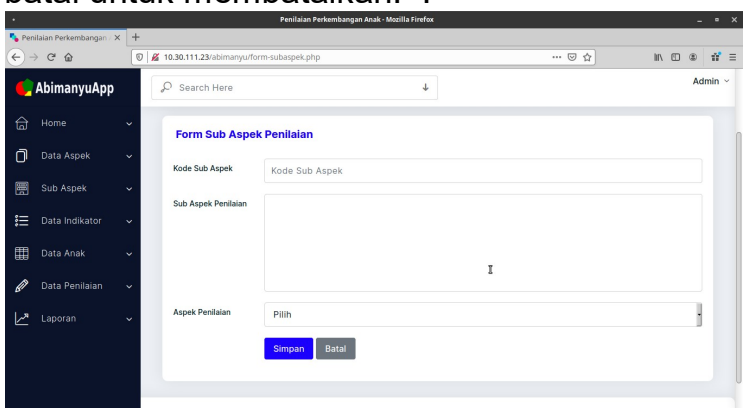

Gambar 12. Input Subaspek Penilaian

\subsubsection{Input Indikator Penilaian}

Dalam menu data indikator penilaian dapat dilakukan penambahan data dengan cara mengisikan data kode indikator, indikator kemudian pilih sub aspek dan klik tombol simpan untuk menyimpan data. Klik tombol batal untuk membatalkan. Tampilan menu input indikator penilaian dapat dilihat pada gambar 13 dibawah ini.

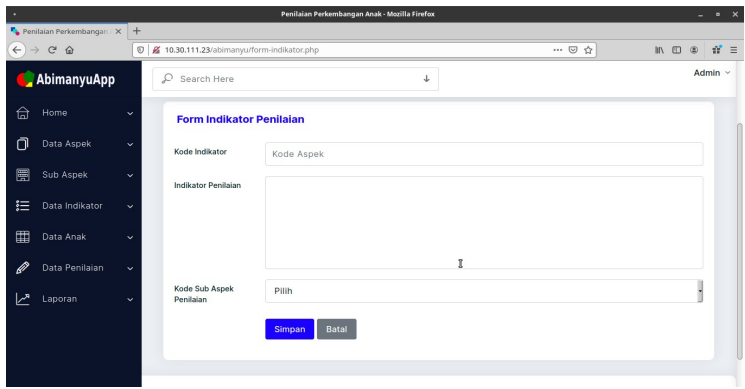

Gambar 13. Input Indikator Penilaian

\subsubsection{Input Data Anak}

Untuk penambahan data anak dapat dilakukan penambahan melalui menu berikut. Caranya dengan mengisikan data nomor induk, nama, jenis kelamin, tanggal lahir, umur, berat, tinggi kemudian klik tombol simpan untuk menyimpan data. Klik tombol batal untuk membatalkan. Tampilan menu input Data Anak dapat dilihat pada gambar 14 berikut :

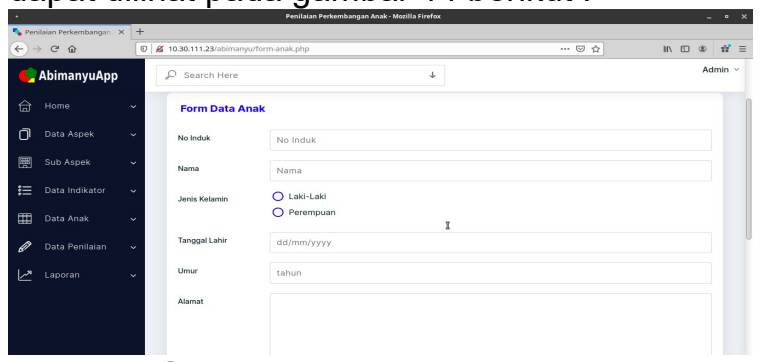

Gambar 14. Input Data Anak

\subsubsection{Input Nilai}

Input nilai terdiri dari nilai harian dan rekap nilai semesteran. Tampilan menu input data nilai harian dapat dilihat pada gambar 15. Penambahan data nilai dapat dilakukan melalui menu ini. Isikan tanggal, bulan, tahun ajaran, semester, nomor induk, indikator penilaian, hasil karya dan capaian nilai kemudian klik tombol simpan untuk menyimpan data. Klik tombol batal untuk membatalkan.

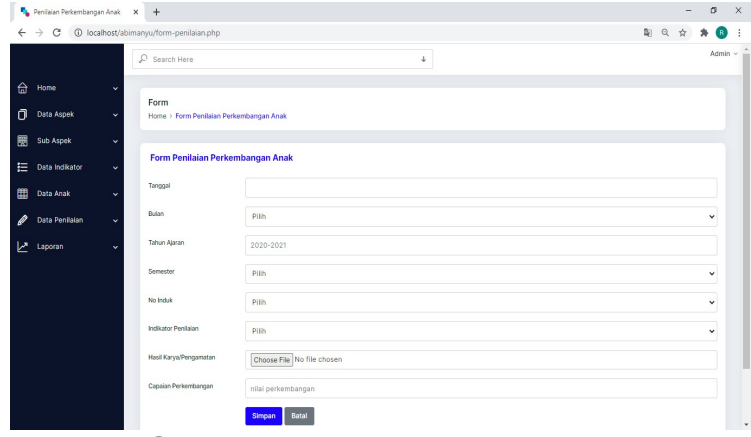

Gambar 15 . Input Nilai Harian

Rekap nilai dapat dilakukan di akhir semester dengan melihat data anak kemudian klik Action kmudian berikan nilai akhir. Rekap nilai dapat di lihat pada gambar 16 .

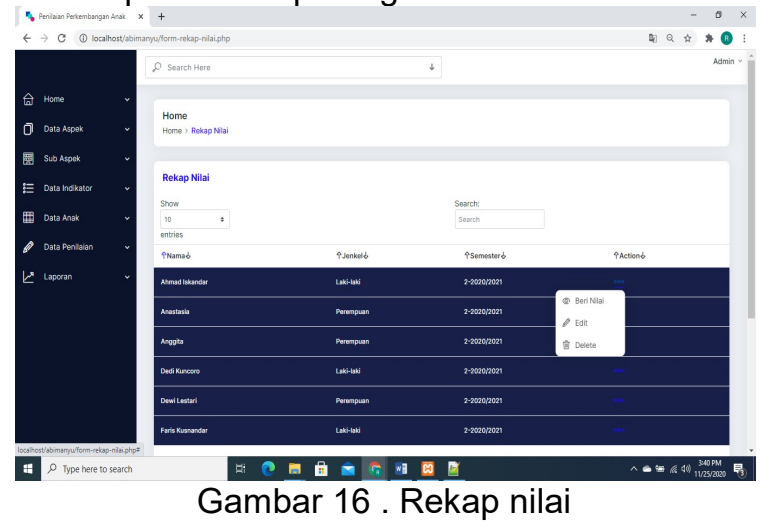

\subsubsection{Pengelolaan Laporan}

Dalam pengelolaan laporan terdapat pilihan laporan data nilai akhir. Untuk mencetak hasil laporan tinggal dipilih print. Jika hanya ingin mencetak per anak didik dapat dilakukan filter dengan mengetikkan nama anak di bagian search. Tampilan pengelolaan laporan dapat dilihat pada gambar 17 dibawah ini :

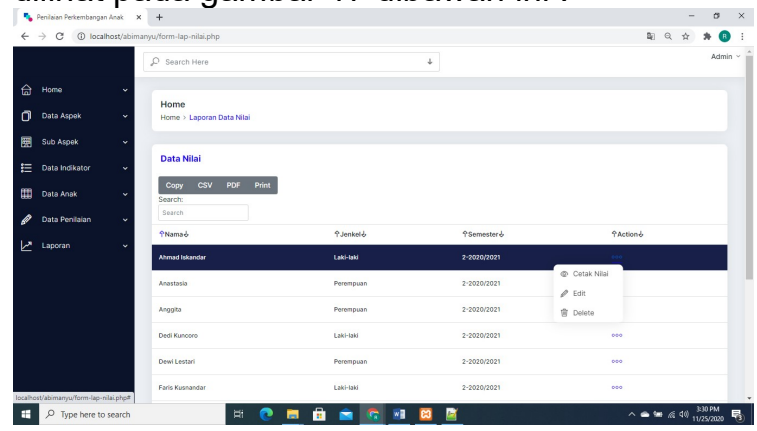

Gambar 17. Pengelolaan Laporan Nilai 


\section{KESIMPULAN}

Dari hasil penelitian yang dilakukan maka dapat di ambil kesimpulan bahwa :

a. Telah di hasilkan aplikasi sistem penilaian perkembangan anak pendidikan usia dini berbasis web dengan hasil Aplikasi yang dapat digunakan untuk mengelola penilaian perkembangan anak mulai dari penambahan data aspek, data indikator, data anak, sampai dengan penilaian baik nilai harian maupun nilai semesteran.

b. Dengan adanya aplikasi ini maka dapat mempermudah guru dalam mengelola penilaian perkembangan anak didik, guru tinggal input data dan akan langsung menghasilkan laporan yang cepat dan akurat.

\section{PUSTAKA}

Erliyani, I., \& Putri, M. T. (2019). Perancangan Sistem Informasi Penilaian Siswa Taman Kanak-Kanak Pada Ra . Darussalam Tangerang. Jurnal Strategic of Education in Information System, 5(2), 142-152.

Febrialismanto, H. N. (2020). PAUD Lectura: Jurnal Pendidikan Anak Usia Dini, Vol 3, No 2, April 2020. 3(2), 40-53.

Gomes, F. De. (2019). Analisis Kesulitan Guru Paud Dalam Menilai. JURNAL Pendidikan Dan Kebudayaan Missio, 11(2 Juli), 293305.

Hani, A. A. (2019). Evaluasi Pembelajaran pada PAUD. Care, 7(1), 52-56.

Hardiyana, A., Kunci, K., Informasi dan Komunikasi, T., \& Usia Dini, A. (n.d.). Optimalisasi Pemanfaatan Teknologi
Informasi Dan Komunikasi Dalam Pembelajaran Paud. 1-12.

Iswantiningtyas, V., \& Wulansari, W. (2018). Pengembangan Model Penilaian Pendidikan Karakter Anak Usia Dini. JPUD - Jurnal Pendidikan Usia Dini, 12(2), 361-370.

https://doi.org/10.21009/jpud.122.17

Jaya, P. R. P. (2019). Pengolahan hasil penilaian pendidikan anak usia dini. Jurnal Lonto Leok Pendidikan Anak Usia Dlini, 2(1), 76-83.

Khairi, H. (2018). e-ISSN: 2550-0058 p-ISSN: 2615-1642. Jurnal Warna, 2(2 Desember), 15-28.

Nurhayati, S., \& Rakhman, A. (2017). Studi Kompetensi Guru Paud Dalam Melakukan Asesmen Pembelajaran Dan Perkembangan Anak Usia Dini Di Kota Cimahi. Jurnal Pendidikan Anak, 6(2), 109-120.

https://doi.org/10.21831/jpa.v6i2.17699

Prabowo, W. S., \& Agustina, C. (2017). Perancangan Sistem Informasi Pengolahan Nilai Rapor Berbasis Web Pada SMK Negeri 1 Purworejo. Jurnal Khatulistiwa Informatika, V(1), 48-57. http://ejournal.bsi.ac.id/ejurnal/index.php/k hatulistiwa/article/view/2288

Utami, A. (2015). Rekayasa Perangkat Lunak. DePublish. 